\title{
مقياس الدافعية للعمل ذو الأبعاد المتعددة: أبعاده، وصدقه، وثباته في السياق التعليمي السعودي
}

\author{
د. صالح علي يعن الله القرني 1" أ. خوش نور خان 2

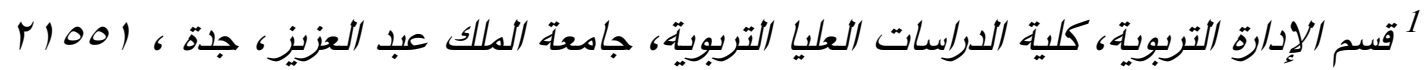 \\ 20قدم الإحصاء، كلية العلوم، جامعة الملك عبد العزيز ، جدة ، 1919 \\ saalqarni@kau.edu.sa الباحث الرئيس:
}

مستخلص. تركز الدراسة الحالية على فحص الخصائص السيكومترية لمقياس الدافعية للعمل ذي الأبعاد المتعددة في السياق التعليمي السعودي، وهي دراسة مستعرضة شملت (9WMS) المكاتب التعليمية بالإدارة العامة للتعليم بجدة، واللذين تم التواصل معهم للحصول على استجاباتهم على مقياس الدافعية للعمل(MWMS). وتم إجراء التحليل العاملي التوكيدي (CFA) لدراسة الخصائص السيكومترية لمقياس Fornell ( الدافعية للعمل (MWMS) \& Larcker,1981). وجرى اختبار الصدق التقاربي باستخدام تقنيتي متوسط التباين المستخلص (AVE) ومعامل

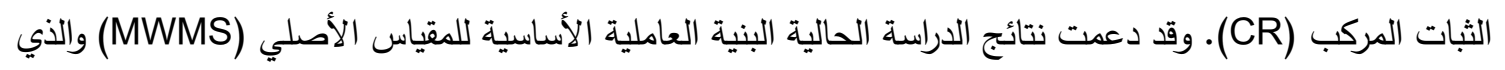

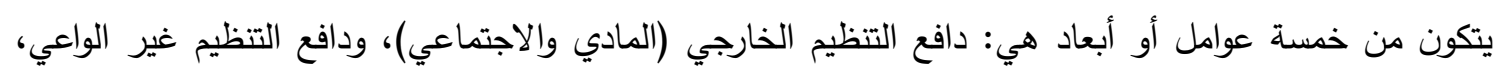

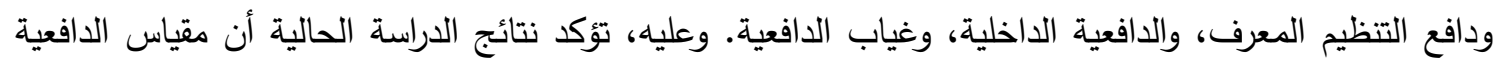

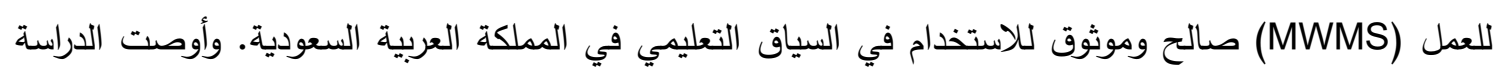
بإجراء دراسات مستقبلية لبحث الثبات والاستقرار الهيكلي لمقياس الدافعية للعمل (MWMS) عبر مؤسسات تعليمية متنوعة في المملكة العربية السعودية، بحيث يمكن تعميمه محليا وكذا على البلدان الأخرى في المنطقة. الكلمات المفتاحية: الدافعية للعمل، الصدق التمايزي، الصدق التقاربي، التحليل العاملي التوكيدي، السياق التعليمي 


\section{Appendix}

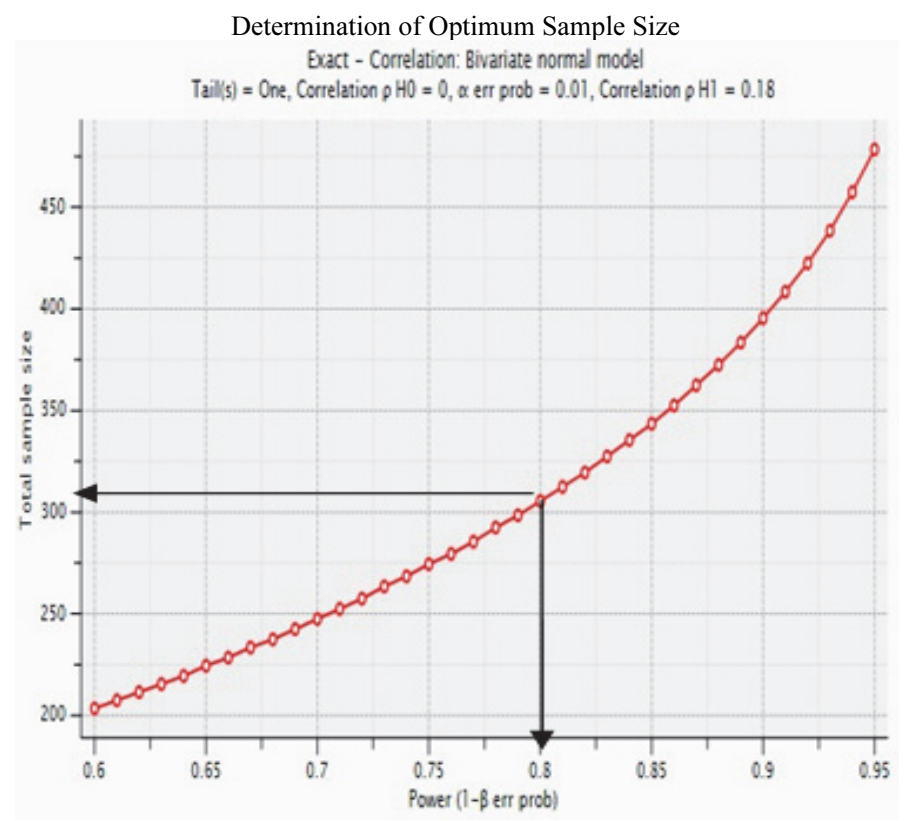


Kappen, F. (2010). Leadership and motivation: How leadership-styles contribute to employees' intrinsic and extrinsic motivation." (Unpublished bachelor degree's thesis). Tilburg University.

Kehr, H. M. (2004). Integrating implicit motives, explicit motives, and perceived abilities: The compensatory model of work motivation and volition. Academy of Management Review, 29 (3), 479-499.

MacCallum, R.C., Browne, M.W., \& Sugawara, H., M. (1996). Power analysis and determination of sample size for covariance structure modeling. Psychological Methods, 1(2), 130-49.

Mohsen, F., Nawaz, M. M., Khan, M., Shaukat, Z., \& Aslam, N. (2004). Are employee motivation, commitment, and job involvement inter-related: Evidence from Banking Sector of Pakistan. International Journal of Business and Social Science, 2(17), 226-233.

Neves, L., \& Coimbra, J.L. (2018). Validation study in the educational context of the Portuguese Version of the Multidimensional Work Motivation Scale. Paidéia, 28,1-8. doi: http://dx.doi.org/10.1590/1982-4327e2803

Nunnally, J.C.(1978). Psychometric theory (2nd ed.). New York: McGraw-Hill.

Osterloh, M., \& Frey, B.S. (2000). Motivation, knowledge transfer, and organizational forms. Organization Science, 11(5), 538550.

Pelletier, L. G., Fortier, M. S., Vallerand, R. J., Tuson, K. M., Brière, N. M., \& Blais, M. R. (1995). Towards a new measure of intrinsic motivation, extrinsic motivation, and amotivation in sports: The sport motivation scale (SMS). Journal of Sport \& Exercise Psychology, 17(1), 35-53

Rahim, M. A., \& Magner, N. R. (1995). Confirmatory factor analysis of the styles of handling interpersonal conflict: First- order factor model and its invariance across groups. Journal of Applied Psychology, $80(1)$, 122 132. https://doi.org/10.1037/00219010.80.1.122

Robbins, S. P., \& Judge, T. A. (2008). Organizational Behavior, 13th edition, Pearson.

Robbins, S.P. (1994). Essentials of Organizational Behavior. New Jersey: Prentice Hall.

Ryan, R.M., Deci, E.L. (2017). SelfDetermination Theory: Basic psychological needs in motivation, development, and wellness. New York: Guilford.

Sonnenfeld, J.A. (1985). Shedding light on the Hawthorne studies. Journal of Occupational Behavior, 6(2), 111-130.

Steiger J.H. (1990). Structural model evaluation and modification: An internal estimation approach. Multivariate Behavioral Research, 25(2), 173-180

Steiger, J.H. (2007). Understanding the limitations of global fit assessment in structural equation modeling. Personality and Individual Differences, 42(5), 893-898.

Thomas, K.W. \& Velthouse, B.A. (1990). Cognitive elements of empowerment: An "interpretive" model. Academy of Management Review, 15(4), 666-681.

Vallerand, R. J., Pelletier, L. G., Blais, M. R., Brière, N. M., Senecal, C., \& Vallieres, E. F. (1992). The Academic Motivation Scale: A measure of intrinsic, extrinsic, and amotivation in education. Educational and Psychological Measurement, 52(4), 10031017.

https://doi.org/10.1177/001316449205200 4025

Woodman, R. W., Sawyer, J. E., \& Griffen, R. W. (1993).Toward a theory of organizational creativity. Academy of Management Journal, 18(2), 293-321. 
Byrne, B. M. (2006). Structural equation modeling with EQS: Basic concepts, applications, and programming. Mahwah, NJ: Lawrence Erlbaum.

Crewson, P.E. (1997). Public-service motivation: Building empirical evidence of incidence and effect. Journal of Public Administration Research and Theory, 7(4), 499-518.

Deci, E. L., \& Ryan, R. M. (1985). Intrinsic motivation and self-determination in human behaviour. New York: Plenum.

Deci, E. L., \& Ryan, R. M. (2000). The 'what' and 'why' of goal pursuits: human needs and the self-determination of behavior. Psychological Inquiry, 11 (4), 227-268. https://doi.org/10.1207/S15327965PLI110 4 _01.

Denton, K. (1987). Effective appraisals: Key to employee motivation. Industrial Engineering, 19 (12), 24-30.

Dwivedula, R., Bredillet, C., \& Müller, R. (2013). Work motivation as a determinant of organizational and professional commitment in case of temporary organizations: Theoretical perspectives. Journal of Project, Program \& Portfolio Management, 4 (1) 11-29.

Fornell, C., \& Larcker, D. (1981). Evaluating structural equation models with unobservable variables and measurement error. Journal of Marketing Research, 18 (1) $39-50$.

Gagné, M., \& Deci, E. (2005). Selfdetermination Theory and Work Motivation. Journal of Organizational Behaviour, 26(4), 331-362.

Gagné, M., Forest, J., Gilbert, M.H., Aubé, C., Morin, E., \& Malorni, A. (2010). The motivation at work scale: Validation evidence in two languages. Educational and Psychological Measurement, 70(4), 628-646.

Gagné, M., Forest, J., Vansteenkiste, M., Crevier-Braud, L.,Van den Broeck, A.,
Aspeli, A. K., ...Westbye, C. (2015). The Multidimensional Work Motivation Scale: Validation evidence in seven languages and nine countries. European Journal of Work and Organizational Psychology, 24(2) 178-196.

George, L., Sabapathy T. (2011). Work motivation of teachers: relationship with organizational commitment. Canadian Social Science, 7 (1) 90-99.

Guay, F., Vallerand, R. J., \& Blanchard, C. (2000). On the assessment of situational intrinsic and extrinsic motivation: The Situational Motivation Scale (SIMS). Motivation and Emotion, 24(3), $175-$

213. https://doi.org/10.1023/A:100561422 8250

Hair, J. F., Black, W. C., Babin, B. j., \& Anderson, R. E. (2010). Multivariate data analysis (7th ed). Upper Saddle River (NJ): Pearson Prentice Hall.

Herzberg, F., Mausner, B., \& Snyderman, B. B. (1959). The Motivation to Work. New York: John Wiley \& Sons.

Hinkin, T. R., Tracey, J. B., \& Enz, C. A. (1997). Scale construction: Developing reliable and valid measurement instruments. Journal of Hospitality and Tourism Research, 21(1), 100-121.

Hooper, D., Coughlan, J., \& Mullen, M. R, (2008). Structural equation modelling: guidelines for determining model fit. The Electronic Journal of Business Research Methods, 6 (1), 53-60.

$\mathrm{Hu}$, L.T. and Bentler, P.M. (1999). Cutoff criteria for fit indexes in covariance structure analysis: Conventional criteria versus new alternatives. Structural Equation Modeling: A Multidisciplinary Journal, 6(1), 1-55. DOI: $10.1080 / 10705519909540118$

Jöreskog, K. \& Sörbom, D. (1996). LISREL 8: User's reference guide. Chicago, IL: Scientific Software International Inc. 
educational and public sectors are advised to use this instrument as a complementary tool in assessing employees' motives, selection procedures of candidates, redesign of job requirements, realign of award and compensation systems, and other work-related interventions.

\section{Conclusion}

The current study provides evidence concerning the psychometric properties of the MWMS using data of 309 educational supervisors working in six educational offices located in six districts of Jeddah, Saudi Arabia. The instrument exhibited a five-factor structure, consisting of 19 items with external regulation as a second-order factor encompassing material and social first-order factors. The MWMS has satisfactory reliability and validity and fits for use in the Saudi educational context.

\section{Limitations/Future Implications}

a. The present study focused only on assessing the psychometric properties of MWMS, and as such, the relation of the five dimensions with some work-related constructs has not been undertaken. To reach a deeper understanding of the MWMS contingency framework (moderation and mediation) with some work-related constructs may be carried out in the future.

b. CFA is used to assess the psychometric properties of MWMS, but CFA is theorydriven and, as such, follows a quantitative deductive approach. In future studies, some semi-structured questions may be added to elicit respondents' perceptions more explicitly, not just restricted to or bounded by a Likert scale.

c. Though the present study just relied on the perceptions of only one class of professionals -educational supervisors, future studies can be conducted to study the structural stability of MWMS across varied occupations.

\section{Author Contributions}

Conceived material, instrument, data collection, discussion, and implications were done by S. Alqarni. Analyses of the data, selection of appropriate statistical tools, and result reporting were done by K. Khan.

\section{Acknowledgments}

This work is supported by the Deanship of Scientific Research (DSR) at King Abdulaziz University, Jeddah, under grant No. (G: 1270324-1440). The authors, therefore, gratefully acknowledge the DSR technical and financial support.

\section{References}

Amabile, T.M. (1993).Motivational synergy: Toward new conceptualizations of intrinsic and extrinsic motivation in the workplace. Human Resource Management Review, 3 (3), 185-201.

Battistelli, A., Galletta, M., Odoardi, C., Núñez, J., \& Ntalianis, F. (2017). Proposal for a version of MWMS across Mediterranean countries: A validation study in Greece, Italy, and Spain. European Journal of Psychological Assessment, 33(2):104-115. DOI: $10.1027 / 1015-5759 / \mathrm{a} 000277$

Bentler, P. M. (1990). Comparative Fit Indexes in Structural Models. Psychological Bulletin, $\quad 107, \quad 238-246$. http://dx.doi.org/10.1037/00332909.107.2.238

Blais, M. R., Brière, N. M., Lachance, L., Riddle, A. S., \& Vallerand, R. J. (1993). L'inventaire des motivations au travail de Blais [Blais's work motivation inventory]. Revue Québécoise de Psychologie, 14, 185-215. 


\section{Discussion}

This paper focused on the adaptation and validation of the MWMS in a Saudi educational context, a theory-based self-determination scale, which had been previously validated in seven different languages and nine countries (Gagné et al., 2015). This current research paper is also in line with other recent attempts, such as Neves \& Coimbra (2018), who adapted and validated the scale in the Swedish educational context, and Battistelli et al. (2017), who conducted a validation study of the MWMS across Mediterranean Countries.

The present study examined the psychometric properties of MWMS consisting of five factors having 19 items in a Saudi educational context. All factors are first-order factors except external regulation, which is studied as a second-order factor by combining material and social as first-order factors. The results of the present study verified that the items that constitute the MWMS are good indicators of the constructs under analysis and that the factors are adequately individualized, matching those observed by Gagné et al. (2015). The current study demonstrated five robust dimensions of MWMS that support a broad understanding of work motivation in the Saudi Context. These factors were also observed in other studies (Neves \& Coimbra, 2018; Battistelli et al., 2017). Concerning reliability, the MWMS exhibited acceptable scores in terms of discriminant and convergent validity. The resulting values in this study are in line with those of the original scale constructed by Gagné et al. (2015) and are consistent with results confirmed by Neves \& Coimbra (2018) and Battistelli et al. (2017).

In sum, the Arabic version of MWMS exhibited good adjustment indices, like the original version developed by Gagné et al.
(2015) and other equivalent versions validated by Neves \& Coimbra (2018) and Battistelli et al. (2017). It shared the same structure with previous versions in other languages, reflecting common cultural idiosyncrasies and influences. Thus, our study verified the multidimensional structure for an instrument that reliably assesses employees' work motivation in the Saudi Arabian educational context.

\section{Practical Implications}

Based on the increased popularity that the MWMS has gained since its emergence in 2015, this paper provides an Arabic version of the scale that can explain employee behavior at the workplace and determine the effects of these motives on individuals and organizations in Saudi educational contexts. The Arabic version will be the first such measure to offer guidance for further studies aiming to study antecedents and consequences of work motivation in Saudi Arabia and Arab countries. As work motivation has long been proved as an influential contributor to a wide range of organizational outcomes, the Arabic version of the MWMS can help investigate different outcomes related to employees' different motives. Moreover, having a reliable Arabic version of the MWMS could help educational leaders address problem areas that may negatively affect teachers and other educators' performance, commitment, and productivity in the work environment. Hence, necessary decisions and initiatives may be taken to rectify such sources of imbalance. Assessing teachers' and educators' motivation through the MWMS, top educational management and policymakers would have valuable insight and information to implement programs that develop teachers' motivational state, which in turn could lead to an improvement of both the teaching process and teachers' psychological health. Human resource managers in 


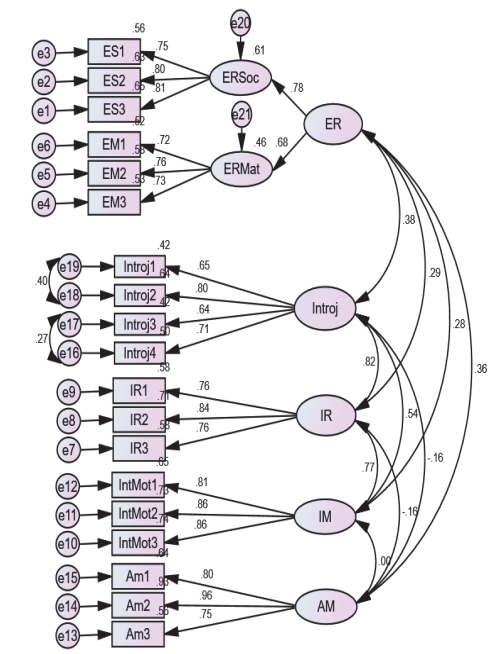

Figure 2. Showing Confirmatory Factor Analysis for Five Factor Structure for MWMS

Table 2. Fit Statistics for Measurement Model of MWMS Instrument

\begin{tabular}{|c|c|c|c|c|c|c|}
\hline$($ CFA $)$ & $\chi^{2} / \mathrm{df}$ & GFI & CFI & RMSEA & AIC & BCC \\
\hline $\begin{array}{c}\text { Five } \\
\text { Factors }\end{array}$ & 2.33 & 0.90 & 0.94 & $\begin{array}{c}0.066 \\
(0.056-0.075)\end{array}$ & 425.0 & 433.13 \\
\hline
\end{tabular}

Table 3. Shows Discriminant, Convergent Validity and Reliability using CR for MWMS Instrument

\begin{tabular}{|c|c|c|c|c|c|c|c|c|}
\hline & CR & AVE & Introj & IR & IM & AM & ER & $\sqrt{\text { Ave }}$ \\
\hline Introj & 0.79 & 0.50 & 0.70 & & & & & 0.71 \\
\hline IR & 0.83 & 0.62 & 0.82 & 0.79 & & & 0.80 \\
\hline IM & 0.88 & 0.71 & 0.55 & 0.77 & 0.84 & & & \\
\hline AM & 0.87 & 0.71 & -0.15 & -0.15 & -0.00 & 0.84 & & 0.84 \\
\hline ER & 0.69 & 0.53 & 0.38 & 0.28 & 0.27 & 0.35 & 0.73 & 0.73 \\
\hline
\end{tabular}

Fornell and Larcker (1981) state that to check discriminant validity, the square root of AVE should be higher than the correlations involving the constructs. Except for IR and Introj (0.82), all correlations involving the constructs have values less than the square root of AVE, but according to Rahim and Magner (1995), it can be ignored. Hence, we can say that the overall discriminant validity of the measurement model is acceptable and supports the discriminant validity between the subscales. This point is well exhibited in Figure 1 as no factor loads on the items of another factor, i.e., there are no cross-factor loadings.

Inter-item consistency is measured through Cronbach's Alpha, and the results are displayed in Table 4. The values of the Cronbach's alphas for all subscales of MWMS lie within the range (0.780 - 0.876), which according to Nunnally (1978), are satisfactory.

Table 4. Inter-item Consistency (Cronbach's Alpha)

\begin{tabular}{|c|c|c|}
\hline Subscales & No of Items & Cronbach's Alpha \\
\hline Introj & 4 & 0.825 \\
\hline IR & 3 & 0.823 \\
\hline IM & 3 & 0.876 \\
\hline AM & 3 & 0.872 \\
\hline ERSoc & 3 & 0.827 \\
\hline ERMat & 3 & 0.780 \\
\hline
\end{tabular}


with the increase in the sample size, the $\chi^{2}$ consequently provides for a good fit (Hinkin et al., 1997). Because of this drawback of the $\chi^{2}$, some alternative metrics were developed to assess the GOF (Hooper et al., 2008). Two indices were used as alternative strategies to study the GOF in the present study, namely, Goodness of Fit Index (GFI) and Comparative Fit Index (CFI), as proposed by Jöreskog, and Sörbom (1996), and Bentler (1990). Apart from the indices, another significant measure to assess the GOF was proposed by Steiger (1990), and that is the Root Mean Square Error of Approximation (RMSEA). The range of GFI and CFI values lies between ( 0 and 1$)$, but $\mathrm{Hu}$ and Bentler (1999) have recommended 0.90 as the GFI and CFI cut-off point. However, Steiger (2007) has suggested an upper limit for RMSEA at 0.07. RMSEA is a double-edged weapon; it tackles the model complexity and discrepancy at the same time. Another significant feature of RMSEA is that one can calculate the confidence interval for a RMSEA score and is always reported along with RMSEA score, which lends more credibility (MacCallum et al., 1996).

Factor loadings of the measurement model for the MWMS scale are exhibited in Figure 2, whereas model fit statistics are presented in Table 2. According to Hair et al. (2010), a tolerable factor loading value 0.5 and above is considered suitable for one indicator. By looking at Figure 1, it is witnessed that all factor loadings are within the range of $(0.64-0.96)$, suggesting a reasonably good measurement structure. Looking at the $\chi^{2}$ statistic for six factors, measurement model, it is apparent that the model does not fit the data well, nevertheless looking at the alternative indices GFI, CFI, and RMSEA, we see that these match the suggested limits proposed by $\mathrm{Hu}$ and Bentler (1999) and Steiger (2007).

Though the results are not as ideal as they should have been but keeping in view the cut- off points discussed in the preceding paragraph and looking at the values of three indices, GFI, CFI, and RMSEA, it is suggested that the model fit is at an acceptable level.

\subsection{Validity and Reliability}

Fornell and Larcker (1981) suggest that convergent reliability can be assessed through "Average Variance Extracted (AVE)" and "Composite Reliability (CR)". CR is also used in place of Cronbach's Alpha, as it is a less biased estimate. Hair et al. (2010) suggest that a value of CR should be at least 0.70 . Results of $\mathrm{CR}$ for the current study are displayed in the first column of Table 3. CR values are also used to assess convergent validity. CR values for the current study range from (0.69 to 0.88$)$, which according to Hair et al. (2010), are satisfactory. Hence, the convergent validity of the MWMS is satisfactory. AVE measures the level of variance captured by a construct versus the level due to measurement error, values that are above 0.7 are good, whereas the level of 0.5 is acceptable (Hair et al., 2010). 


\section{Results}

\subsection{Sampling Characteristics}

The socio-demographic profile of the respondents is given in Table 1. An optimum sample of 309 educational supervisors from six educational offices located in six zones of Jeddah was selected using G-power software. Three parameters are used in determining the optimum sample size: a. Effect size, b. Level of significance $(\alpha)$, and $c$. Power of the test (1- $\beta)$. For the present study a moderate effect size of $(r=0.18), \alpha=0.01$ and $1-\beta=0.80$ were considered. Though a sample size of 306 was suggested by the graph shown in Appendix but to be on the safe side, 401 questionnaires were distributed, and after discarding incomplete questionnaires, data from 309 questionnaires were used for analyses. Of these, 187(60\%) were females, and $122(40 \%)$ were males. Regarding age groups, the majority, 256(82\%), were aged between 35-50. As for the length of service, the majority (71.8\%) of the respondents have worked for more than 20 years. In terms of qualifications, $201(65 \%)$ hold a bachelor's degree, whereas $108(35 \%)$ have postgraduate degrees.

Table 1. Socio-Demographic Profile of the Respondents

\begin{tabular}{|c|c|c|c|}
\hline & & $\mathrm{n}$ & $\%$ \\
\hline \multirow{6}{*}{ Office } & North & 89 & 28.8 \\
\hline & East & 51 & 16.5 \\
\hline & South & 78 & 25.2 \\
\hline & Middle & 53 & 17.2 \\
\hline & Alsafa & 16 & 5.20 \\
\hline & Alnaseem & 22 & 7.10 \\
\hline \multirow{2}{*}{ Gender } & Female & 187 & 60.5 \\
\hline & Male & 122 & 39.5 \\
\hline \multirow{3}{*}{ Age Groups } & Less than 35 & 3 & 1.00 \\
\hline & $35-50$ & 256 & 82.8 \\
\hline & $>50$ & 50 & 16.2 \\
\hline \multirow{3}{*}{ Length of Service } & Less than 10 years & 19 & 6.10 \\
\hline & $10-20$ & 68 & 22.0 \\
\hline & $>20$ & 222 & 71.8 \\
\hline \multirow{2}{*}{ Educational Qualification } & Bachelors & 201 & 65.0 \\
\hline & Postgraduate & 108 & 35.0 \\
\hline
\end{tabular}

\subsection{Confirmatory Factor Analysis}

Confirmatory Factor Analysis (CFA) and Exploratory Factor Analysis (EFA) are used to assess a set of items whether they hang together as one scale or not. These tools are used as dimension reduction techniques. Comparatively, CFA is more advantageous as it also quantifies whether the model fits the data well or not, which is commonly known as "Goodness-of-fit" (GOF) in statistical parlance. A CFA was performed to test the model consisting of six factors with External Regulation treated as a second-order factor encompassing social and material extrinsic regulations, as proposed by Gagné et al. (2015). CFA was employed as an appropriate statistical technique for assessing the psychometric properties of MWMS and whether the proposed structure fits the data well in the Saudi educational context. The most appropriate index to assess the goodness of fit is Chi-square $\left(\chi^{2}\right)$ but is quite dependent on sample size, i.e., 
The present study replicates the dimension structure given by Gagné et al. (2015), who treated amotivation, intrinsic motivation, introjected regulation, and identified regulations as first-order factors and external regulation as a second-order factor by combining material and social first-order factors. Researchers should keep in mind that while studying a phenomenon using structural equation modeling (SEM), oval figures depict a latent variable that is formed by the combination of some observed variables (latent variables), which are directly collected through any instrument. Rectangles depict observed variables in the SEM. Single-headed arrows in the measurement models depict the factor weights, and double-headed arrows depict correlation among the latent variables. The basic conceptual framework is shown in Figure 1. CFA in the present study was conducted following the guidelines provided by Byrne (2006).

\subsection{Format of the Paper}

The rest of the paper proceeds as follows: Section 2 discusses the research design, data collection, and statistical analysis strategy adopted to assess the psychometric properties of MWMS, section 3 elaborates the results obtained through the application of the statistical strategy, sections 4 and 5 discuss the outcomes of the current study along with some practical implications viz-a-viz a Saudi educational context, sections 6 and 7 briefly concludes the study with some future implications.

\section{Methods and Materials}

\subsection{Research Design/Method}

This study adopted a quantitative crosssectional design, and the perceptions of respondents were elicited through a selfadministered questionnaire.

\subsection{Research Setting/Data Collection}

For data collection, six educational offices located in Jeddah were approached during the second term 2017/2018, and the target respondents were educational supervisors. Respondents were assured about confidentiality and anonymity. Online questionnaires were sent to 401 educational supervisors who represent the original population. Three hundred nine supervisors responded; thus, the response rate was $78 \%$.

\subsection{Instrument}

Gagné et al. (2015) has developed the MWMS in seven languages and nine countries. The MWMS encompasses five dimensions: amotivation, extrinsic regulation (social and material), identified regulation, and introjected regulation. Factorial analyses indicated that their 19-item scale has the same factor structure across the seven languages. The translation and back-translation method was carried out to increase the respondents' comprehension of the original questionnaire. The MWMS was presented as statements, and respondents were asked to rate each statement along a seven-point Likert scale where $1=$ "not at all", 2 = "very little", 3 = "a little", 4 = "moderately", $5=$ "strongly", $6=$ "very strongly", $7=$ "completely".

\subsection{Statistical Analysis Strategy}

To assess the validity of MWMS, Confirmatory Factor Analysis (CFA) was carried out using two statistical software SPSS version 23.0 and AMOS version 19.0. The socio-demographic profile of the respondents encompassing five aspects were exhibited. Composite reliability (CR) of the scale was conducted using the procedure given by Hair et al. (2010). 
Switzerland, China, and Indonesia). Factorial analyses indicated that their 19-item scale has a five-factor structure across the seven languages; the five dimensions of MWMS are "amotivation, external regulation (social and material), introjected regulation, identified regulation and intrinsic motivation." All five dimensions stem from (SDT), and they are briefly enumerated as follows: extrinsic regulation refers to "engaging in the activity for instrumental reasons, such as receiving rewards and approval, avoiding punishments or criticism, boosting one's self-esteem, or reaching a personally valued goal" (Gagné et al., 2015, p. 179). This construct encompasses two subtypes of regulations: "the social and material extrinsic regulation". Introjected regulation refers to "partial internalization in which regulations are in the person but have not really become part of the integrated set of motivations, cognitions, and affects that constitute of the self" (Deci \& Ryan, 2000, p.236). Identified regulation refers to "doing an activity because one identifies with its value or meaning, and accepts it as one's own, which means that it is autonomously regulated" (Gagné et al., 2010, p.629). Intrinsic motivation is seen as "doing something for its own sake because it is interesting and enjoyable" (Gagné et al., 2010, p.629). Amotivation results in the non-existence of motivation for an activity. Since its emergence in 2015, the MWMS has received widespread attention from researchers and professionals interested in work motivational issues. Gagné et al. (2015) argued that the MWMS has gathered several merits; it has undergone careful and rigorous processes with regard to selection of items, invariance analysis, and sampling procedures. One another strength of the MWMS is its heterogeneity and applicability across different cultural and organizational contexts (Gagné et al., 2015). Recent researchers (Neves \& Coimbra, 2018; Battistelli et al., 2017) stated that MWMS outweighs other contemporary scales in four areas - based on a well-established theory (SDT), inclusion and balancing of approach and avoidance motives, no cross-over of items to other constructs and cross-cultural structural invariance.

\subsection{Conceptual Framework}

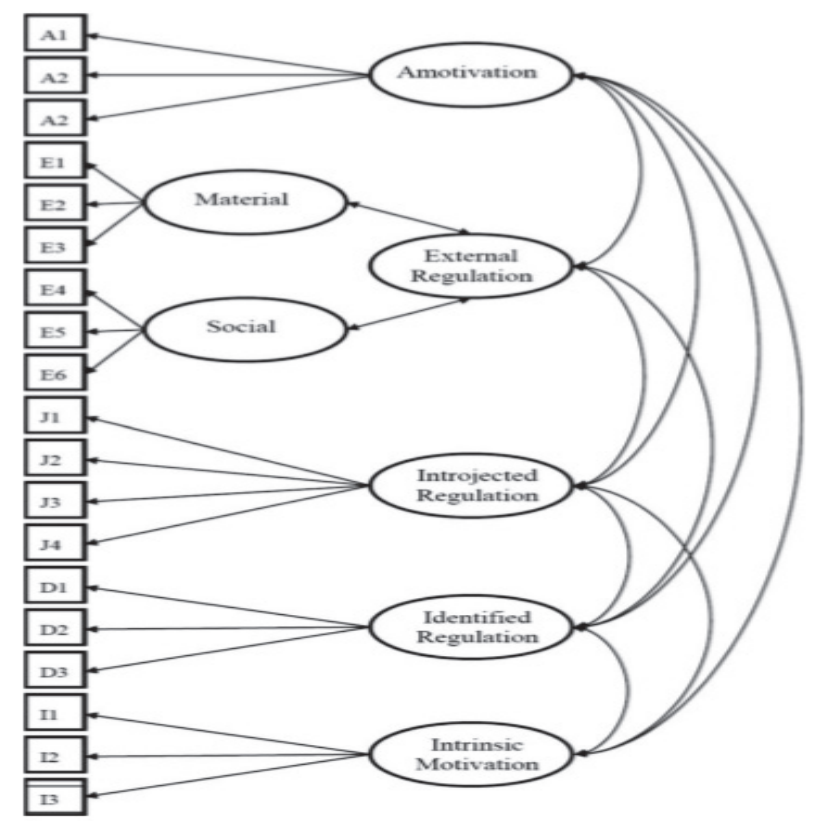

Figure 1. Five-Factor Structure for MWMS (Source: Gagné et al., 2015) 
that "intrinsic motivation" is superior to "extrinsic motivation" under specific conditions, but Amabile (1993) and Kappen (2010) argue that both types often co-occur for one specific task.

Employees' motivation has been verified to contribute to positive organizational outcomes. Highly committed and motivated employees are critical to any organization as they work with their utmost zeal for the betterment of the organization (Denton, 1987). Crewson (1997) provides evidence that employee motivation is directly linked to organizational commitment. Moreover, work motivation leads to better decision-making (Mohsen et al., 2004). Intrinsic motivation is a significant factor for employees' innovative work behavior (Woodman et al., 1993). Intrinsically motivated employees are deemed to be better at focusing on their work activities (Deci \& Ryan, 2000) and more likely to translate their motivations into higher levels of work performance (Kehr, 2004).

Considering motivation at work as an influential contributor to a wide range of positive outcomes, many research works have aimed to develop valid and reliable measures to assess employees' motivation in different work contexts. Most of these validated measures are SDT-based motivation scales (e.g. (Guay et al., 2000; Pelletier et al., 1995; Vallerand et al., 1992). As for the work domain, Blais et al. (1993) developed the first SDT-based work motivation scale in French. Gagné et al. (2010) introduced their Motivation at Work Scale in two languages. It posited that the structure of motivation at work across languages is consistently organized into four different types: intrinsic motivation, identified regulation, introjected regulation, and external regulation (Gagné et al., 2010). In 2015, Gagné et al. (2015) developed the MWMS and assessed its psychometric properties using data collected from nine countries in seven languages. The authors conducted the invariance analyses to assess whether the scale structure remains the same across different languages under study. It gives more credence to MWMS that its items are comprehended in the like manner across seven languages. In Gagné et al. (2015), the relation of the five dimensions of MWMS with some work-related antecedents and outcomes was also carried out. Driven by the merits of MWMS, Neves \& Coimbra (2018) adapted and validated the scale within the Swedish educational context. Likewise, Battistelli et al. (2017) conducted a validation study of the MWMS across Mediterranean Countries, namely Greece, Italy, and Spain. To the authors' knowledge, no other validated scale exists, which is tested with several languages coupled with the complex factor structure as the MWMS.

While going through literature research, the authors have not come across any study, which has studied the psychometric properties of MWMS in a Middle Eastern educational milieu. The present study intends to explore motivation at work among educational supervisors working in the Kingdom of Saudi Arabia. Based on the literature review, the primary objective of the current study is to assess the psychometric properties of MWMS in the educational context of Saudi Arabia.

\subsection{The Multidimensional Work Motivation Scale (MWMS)}

Gagné et al. (2010) introduced their Motivation at Work Scale (MAWS) in two languages (French and English). They posited that the structure of motivation at work across languages is consistently organized into four latent factors: intrinsic motivation, identified regulation, introjected regulation, and external regulation (Gagné et al., 2010). Five years later, Gagné et al. (2015) presented an improved version of MAWS, the MWMS, which was validated using seven languages and in nine countries (i.e., Canada, Belgium, France, Senegal, United Kingdom, Norway, 
surrounding context (Osterloh \& Frey, 2000). Therefore, motivators are known as intrinsic factors and hygiene-factors as extrinsic factors (Amabile, 1993).

Employees are a vital ingredient to any organization because they can make or break an organization depending upon their willingness to work. This willingness to work is well known as work motivation in the context of an organization (Robbins \& Judge, 2008). The work motivation is formally defined by Robbins (Robbins, 1994, p.42) as "the willingness to do something and conditioned by the action's ability to satisfy some need of the individual".

Guided by the philosophy of the selfdetermination theory (SDT), several models and frameworks of work motivation have emerged, yet all frameworks that have been studied so far acknowledge one theme that there are extrinsic and intrinsic motivational factors (Thomas \& Velthouse, 1990; Mohsen et al., 2004; Gagné \& Deci, 2005; Dwivedula et al., 2013; George \& Sabapathy, 2011). SDT provides a holistic framework of human motivation that has been effectively applied across contexts including education, healthcare, sports, psychotherapy, and virtual worlds, as well as the fields of work motivation and management (Ryan \& Deci, 2017; Deci \& Ryan, 1985).

\subsection{Self-Determination Theory (SDT)}

Self-determination theory (SDT) was crafted by two psychologists Edward Deci and Richard Ryan, who originally presented their thoughts in their 1985 book "Self-Determination and Intrinsic Motivation in Human Behavior" (Deci \& Ryan, 1985). SDT is a significant framework that emphasizes each person's capacity to have options to make a choice and to control their own life (Deci \& Ryan, 1985). Selfdetermination affects the motivation level of an individual, who feels increasingly persuaded to make a change when he feels that what he does will have a positive bearing on the activity undertaken. The theory of motivation stems from SDT, which suggests that individuals are driven by a need tend to grow and reach fulfillment. SDT has been recently applied to determine the motives, conditions, and drivers stimulating employees to behave in different ways in their work environments (Gagné \& Deci, 2005; Deci \& Ryan, 1985). SDT postulates that motivation is a multidimensional concept and suggests how the dimensions of motivation can be enhanced or discouraged (Gagné et al., 2015). Three main dimensions of motivation as envisaged in SDT are amotivation, intrinsic motivation and extrinsic motivation (Gagné \& Deci, 2005; Deci \& Ryan, 1985). There are also three subtypes of extrinsic motivation depending on the internalization of goals or activities at hand, known as external regulation, introjected regulation, and identified regulation (Gagné et al., 2015).

\subsection{Empirical Work}

Employee motivation can be intrinsic and extrinsic (Thomas \& Velthouse, 1990; Mohsen et al., 2004; Gagné \& Deci, 2005; Dwivedula et al., 2013; George \& Sabapathy, 2011). Intrinsic motivation derives from within the person or from the activity itself; doing a task or an activity for its own sake (Deci \& Ryan, 1985). For example, an employee will engage in a work task because it is enjoyable or interesting. In contrast, extrinsic motivation refers to the engagement in a work task for instrumental drivers such as reward, compensation, promotion, recognition, or avoidance of negative consequences (Gagné et al., 2015; Gagné et al., 2010; Deci \& Ryan, 2000).

Intrinsically motivated behaviors are desirable because they occur for the pleasure or the satisfaction derived from engaging in such behaviors. In contrast, extrinsically motivated behaviors occur for instrumental factors such as the sake of a reward or avoiding any negative consequences. Osterloh and Frey (2000) stated 


\title{
The Multidimensional Work Motivation Scale: Dimensionality, Validity and Reliability in a Saudi Educational Context
}

\author{
Saleh Ali Y. Alqarni ${ }^{1, *}$ Khushnoor Khan² \\ ${ }^{1}$ Department of Educational Administration, Faculty of Graduate Educational Studies, King \\ Abdulaziz University, Jeddah, 21551, KSA \\ ${ }^{2}$ Department of Statistics, Faculty of Science, King Abdulaziz University, Jeddah, 21589, KSA \\ *Corresponding author: saalqarni@kau.edu.sa
}

\begin{abstract}
The present study focuses on studying the psychometric properties of the Multidimensional Work Motivation Scale (MWMS) in a Saudi educational context. The study was cross-sectional, comprising 309 educational supervisors from Jeddah's General Directorate of Education, who were contacted through the MWMS to obtain the relevant information. Confirmatory Factor Analysis (CFA) was carried to study the psychometric properties of the MWMS. Discriminant validity was measured using the procedure suggested by Fornell and Larcker (1981). Convergent validity of the measurement model was assessed using the Average Variance Extracted (AVE) and Composite Reliability (CR) techniques. Findings supported the five-factor structure of MWMS: external regulation (social and material), introjected regulation, identified regulation, intrinsic motivation, and amotivation. Hence, suggesting that the MWMS is valid and reliable to use within the educational context in Saudi Arabia. For the scale to be generalized, the present study recommends that future studies be conducted to study the structural stability of MWMS across various educational organizations in Saudi Arabia and other countries in the region.
\end{abstract}

Keywords: work motivation, discriminant validity, convergent validity, confirmatory factor analysis, educational context

\section{Introduction}

The study of work motivation has a long history in literature. The studies of work motivation are traced back to Western Electric's Hawthorne Studies of 1924 (Sonnenfeld, 1985). As Motivation at the workplace plays a vital role in productive output from employees, several studies have been conducted to investigate motives and drivers that contribute to employee motivation. Noticeably, the most recent research builds on the ideas of two of the most widely accepted models of motivation;
Maslow's Hierarchy of Needs, which is based on levels of psychological need priorities, and Herzberg's Two-Factor Model, which presents job factors as contributing to either satisfaction or dissatisfaction. Motivation Hygiene Theory emphasized that motivation is influenced by motivators and hygiene-factors; motivators lead to satisfaction, while hygiene-factors do not motivate if present, but lead to dissatisfaction if absent (Herzberg et al., 1959). Motivators concern the work itself, whereas hygiene-factors have something to do with the 